\title{
Research Article \\ Utilization of a High Fidelity Simulation Experience and Impact on New Nurses' Clinical Judgment
}

\section{Sara Lewandowski}

Department of Nursing, Lone Star College

Cyfair, Texas, United States

\section{*Corresponding Author:}

Dr. Sara Lewandowski, RN, BS, BA, MS, DNP, Department of Nursing, Lone Star College Cyfair, Cypress, United States, Tel: 281-2903506, Email: Sara.Lewandowski@lonestar.edu

Received Date: July 12, 2017

Accepted Date: July 20, 2017

Published Date: July 28, 2017

\section{Citation:}

Sara Lewandowski (2017). Utilization of a High Fidelity Simulation Experience and Impact on New Nurses' Clinical Judgment. POJ Nurs Prac Res 1(1): 1-4.

\section{Abstract}

Clinical judgment skills in the novice nurse population often need support and enhancement through evidence based teaching pedagogies. The research question used to guide this project was "Does utilization of a high fidelity simulation experience impact new nurses' clinical judgment skills as measured over an eight -week period of time"? The practice setting occurred in a large Houston based hospital where there was an academic-clinical affiliation. The outcome objective of at least a ten percent increase in clinical judgment between pre-post interventions was met. The implications of this quality improvement project reinforce what is known about simulation as a reliable teaching pedagogy and validate using high fidelity simulation to enhance new nurses' clinical judgment.

Key words: High fidelity simulation, Clinical judgment, New nurses, Evidence- based teaching pedagogy.

\section{Background}

A teaching pedagogy that supports the demands of modern nursing practice is vital for new nurses' clinical judgment skills. According to the Institute of Medicine (IOM), the rise in the United States morbidity and mortality in health care settings causes public concern about professional competency [4]. In addition, the transparency of data related to patient outcomes requires health care organizations to hire astute, skilled nursing staff who can help overcome these challenges and continually improve the linkage of systematic data of quality nursing care to improved patient outcomes. In addition to quality patient care, lack of clinical judgment skills in new nurses can significantly impact cost for the organization. This quality improvement project contributes to new nursing knowledge because the majority of prior research cites results of high fidelity simulation in the academic setting. This quality improvement project occurred in a large clinical practice setting where high fidelity simulation had never been used.

The research question guiding this project was: does utilization of a high fidelity simulation experience impact new nurses' clinical judgment as measured over an eight- week time period?

Operational definitions of the variables in the research question are important to highlight. Facione and Facione (1996) articulate clinical judgment as an interactive, reflective reasoning process [2]. The key is that the learner must make a purposeful judgment about what to do. Clinical judgment, as measured on the Lasater clinical judgment rubric, also includes the main categories of noticing, interpreting, responding and reflecting [6]. Therefore, all these components can be operationalized as part of clinical judgment. The four categories on the LCJR were originally adopted through Tanner's model of clinical judgment [7]. Lasater (2007a) has also discussed the overlap of the terms "clinical judgment" and "critical thinking" in the literature [5].

Copyright: (C) 2017 Sara Lewandowski, et al. This is an open-access article distributed under the terms of the Creative Commons Attribution License, which permits unrestricted use, distribution, and reproduction in any medium, provided the original author and source are credited. 
New nurses were defined as nurses who were employed two years or less at the time of the intervention who participated in the simulation during the eight- week time frame of implementation. High fidelity simulation was operationalized as computerized manikins that can replicate the human appearance and can be operated to imitate physiologic responses. The comparison was conducted with a quasi-experimental design with a pre-post measurement of clinical judgment as measured by the nurse residents. In an email communication with Dr. Lasater, it was articulated that the LCJR was designed as an instrument to describe the trajectory of nurses' clinical judgment development over the length of a program. The purposes were to offer a common language between students, faculty, and preceptors in order to talk about nurses' thinking and to serve as a help for offering formative guidance and feedback (Lasater, email communication, August 3, 2016).

The short- term objective was for the high fidelity simulation experience to have at least a ten percent increase in clinical judgment over the eight -week project implementation period. The long- term objectives included enhancement of collaboration between nursing education stakeholders and new nurses, easing the transition to practice period for new nurses, and ultimately improving patient and organizational outcomes. The long- term goal impact on prevention of legal issues is applicable because simulation offers the ability to practice nursing in a safe environment without risk of patient harm. The short- term goal of this quality improvement project did identify at least a ten percent increase in clinical judgment following the intervention. As a result, the practice setting has continued to increase the use of high fidelity simulation into their new nurse residency program.

\section{Sample}

This quality improvement project was implemented at a major metropolitan Houston area primary care hospital. The convenience sampling for the population included a cohort of nursing residents and any new nurse employed two years or less who consented to the project during the eight week project implementation phase. The inclusion criteria for the participants were that they were employed by the project site as a nurse for two years or less. There were no other exclusion criteria unless they voluntarily declined to participate in consent of the project. Seven participants consented to the project during the eight week period. The participants worked on medical surgical, emergency, observation and post-partum floors for two years or less. The project was voluntary and IRB approval was obtained from three different institutions.

\section{Method}

The project was a pre-post quasi- experimental design comparing pre-simulation level of clinical judgment to post- simulation level. The evaluation criteria to determine whether the tested change intervention was complete were statistical significance of the returned Lasaster Clinical judgment rubric (LCJR). A significance value was set as $<0.05$. Reliability and validity has previously been determined from using this tool specifically with simulation studies [1]. The Lasaster clinical judgment tool's categories (noticing, interpreting, responding, and reflecting) were coded into categories in SPSS based on the simulation scenario to make an interval scale. The pre-simulation LCJR was completed one week before the simulation experience for the pre -simulation baseline data. Following the simulation, the nurses returned to the clinical practice units for two weeks. After these two weeks of additional clinical time, the LCJR was completed for post -simulation clinical judgment measurement. The overall median score was analyzed using SPSS Wilcoxon test and compared for the two measures. In addition, a paired t-test for all eleven categories of the Lasater clinical judgment tool was used to determine statistical significant change in each category.

\section{Results}

Nurses' clinical judgment was rated on a scale of 1 to 4 at pre-intervention and again at post intervention. The lower the score, the less competent the individual was rated in one of eleven abilities. The 11 scores were averaged for each participant in pre-intervention and again at post -intervention. The dependent variable was ordinal, and the samples were related, so therefore a Wilcoxon Signed Rank Test was used [3].

Expected outcomes stated a 10 percent difference from pre-intervention $(\mathrm{M}=2.56)$ and post intervention $(\mathrm{M}=3.06)$ which is a $16 \%$ increase (Table 1). Therefore, this quality improvement project's short term outcome was met of at least a ten percent overall increase in clinical judgment.

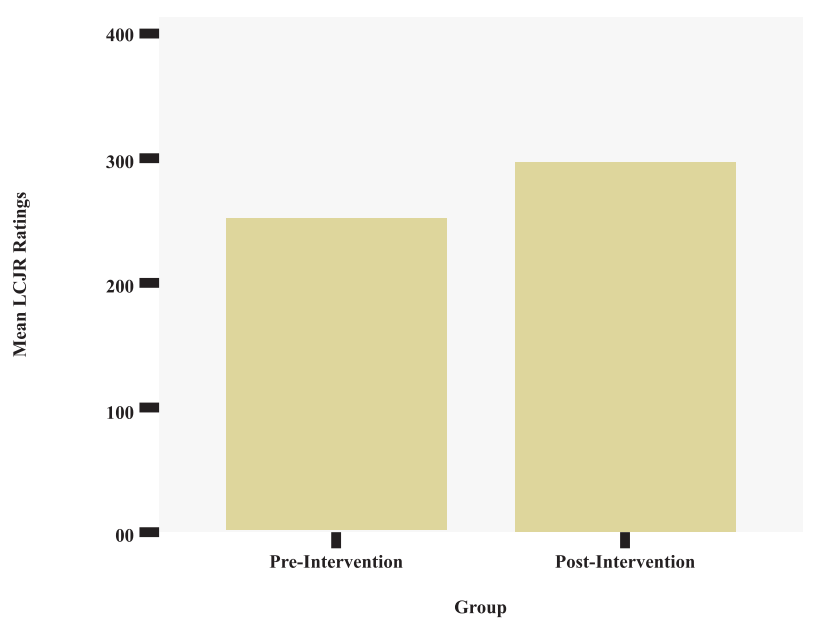

Table-1

In addition, all eleven categories of the Lasater clinical judgment rubric were statistically analyzed using a paired t-test statistical analysis to determine if specific categories of the LCJR had statistical significance (Table 2). There were 11 paired samples t-tests run on the eleven qualities in the LCJR: focused observation, recognizing deviations from expected patterns, information seeking, prioritizing data, making sense of data, calm, confident manner, clear communication, well planned intervention-flexi- 
bility, being skillful, evaluation-self-analysis, commitment to improvement. As seen in Table 2, there was a significant mean increase from pre-intervention to post-intervention on recognizing deviations from expected patterns $(p=0.047)$, information seeking $(p=0.047)$, clear communication $(p=0.008)$, well planned intervention-flexibility $(p=0.045)$ and commitment to improvement $(p=0.030)$. This means that the intervention had a significant impact on these five qualities. It is noted that three categories (recognizing deviations from expected patterns, information seeking, well-planned intervention-flexibility) had borderline statistical significance, which is noted as a limitation to this study.

\section{Table-2}

Wilcoxon Signed Rank Test

\begin{tabular}{|rccc|}
\hline LCJR Post-Intervention - LCJR Pre-Intervention & N & Mean Rank & Sum of Ranks \\
\hline Negative Ranks & $1^{\text {a }}$ & 4.00 & 4.00 \\
\hline Positive Ranks & $6^{\text {b }}$ & 4.00 & 24.00 \\
\hline Ties & $0^{\text {c }}$ & & \\
\hline Total & 7 & & \\
\hline
\end{tabular}

a. LCJR Post-Intervention $<$ LCJR Pre-Intervention

b. LCJR Post-Intervention $>$ LCJR Pre-Intervention

c. LCJR Post-Intervention $=$ LCJR Pre-Intervention

Paired Samples t-tests for the LCJR Scales

\begin{tabular}{|c|c|c|c|c|c|c|c|c|c|}
\hline & & & & ed Differe & ices & & $\mathrm{t}$ & $\mathrm{df}$ & \\
\hline & & Mean & $\begin{array}{c}\text { Std. } \\
\text { Deviation }\end{array}$ & $\begin{array}{l}\text { Std. } \\
\text { Error } \\
\text { Mean }\end{array}$ & $\begin{array}{r}95 \\
\text { Confidence } \\
\text { the Dif }\end{array}$ & $\begin{array}{l}\text { nterval of } \\
\text { rence }\end{array}$ & & & (2-tailed) \\
\hline & & & & & Lower & Upper & & & \\
\hline Pair 1 & $\begin{array}{l}\text { focused observation - } \\
\text { focused observation }\end{array}$ & -.714 & .951 & .360 & -1.594 & .165 & -1.987 & 6 & .094 \\
\hline Pair 2 & $\begin{array}{l}\text { recognizing deviations } \\
\text { from expected patterns } \\
\text { - recognizing deviations } \\
\text { from expected patterns }\end{array}$ & -.714 & .756 & .286 & -1.413 & -.015 & -2.500 & 6 & .047 \\
\hline Pair 3 & $\begin{array}{l}\text { information seeking - } \\
\text { information seeking }\end{array}$ & -.714 & .756 & .286 & -1.413 & -.015 & -2.500 & 6 & .047 \\
\hline Pair 4 & $\begin{array}{l}\text { prioritizing data - } \\
\text { prioritizing data }\end{array}$ & -.429 & .787 & .297 & -1.156 & .299 & -1.441 & 6 & .200 \\
\hline Pair 5 & $\begin{array}{l}\text { making sense of data - } \\
\text { making sense of data }\end{array}$ & -.286 & .488 & .184 & -.737 & .166 & -1.549 & 6 & .172 \\
\hline Pair 6 & $\begin{array}{l}\text { calm, confident manner - } \\
\text { calm, confident manner }\end{array}$ & -.571 & .976 & .369 & -1.474 & .331 & -1.549 & 6 & .172 \\
\hline Pair 7 & $\begin{array}{l}\text { clear communication - } \\
\text { clear communication }\end{array}$ & -.714 & .488 & .184 & -1.166 & -.263 & -3.873 & 6 & .008 \\
\hline Pair 8 & $\begin{array}{l}\text { well planned interven- } \\
\text { tion-flexibility - well } \\
\text { planned intervention-flex- } \\
\text { ibility }\end{array}$ & -.857 & .900 & .340 & -1.689 & -.025 & -2.521 & 6 & .045 \\
\hline
\end{tabular}

Citation: Sara Lewandowski (2017). Utilization of a High Fidelity Simulation Experience and Impact on New Nurses' Clinical Judgment. POJ Nurs Prac Res 1(1): 1-4. 


\begin{tabular}{|c|c|c|c|c|c|c|c|c|c|}
\hline Pair 9 & $\begin{array}{l}\text { being skillful - being } \\
\text { skillful }\end{array}$ & -.429 & .787 & .297 & -1.156 & .299 & -1.441 & 6 & .200 \\
\hline Pair 10 & $\begin{array}{l}\text { evaluation-self analysis - } \\
\text { evaluation-self analysis }\end{array}$ & -.714 & .951 & .360 & -1.594 & .165 & -1.987 & 6 & .094 \\
\hline Pair 11 & $\begin{array}{l}\text { commitment to improve- } \\
\text { ment - commitment to } \\
\text { improvement }\end{array}$ & -.571 & .535 & .202 & -1.066 & -.077 & -2.828 & 6 & .030 \\
\hline
\end{tabular}

\section{Conclusion}

This project reinforces the benefits of using high fidelity simulation with a population of new nurses employed two years or less at a Houston area hospital. This project displayed statistical significance when using the Lasater clinical judgment rubric in several key areas which may impact nursing practice in a positive manner. Limitations of this project include the small sample size due to this being a pilot project and the institution being new to high fidelity simulation practices in the nurse residency program.

Implications for nursing practice as a result of this project reinforce the benefits of using high fidelity simulation in clinical practice with new nurses employed two years or less. In addition, this author suggests extending similar projects to include the potential impact of enhanced clinical judgment on actual patient and organizational outcomes such as patient satisfaction, quality and cost.

\section{References}

1. Chiml J, Larew C. Psychometric properties of the Lasater Clinical Judgment Rubric. Int J Nurs Educ Scholarsh. 2013;10(1):1-8.

2. Facione N, Facione P. Assessment design issues for evaluating critical thinking in nursing. Holist Nurs Pract. 1996;10(3):41-53.

3. Freedman D, Pisani R, Purves R. Statistics. Fourth edition. New York: W.W. Norton, 2011.

4. Institute of Medicine. To err is human: building a safer health system: A report of the committee on quality of health care in America: Washington, DC: National Academy Press; 2012.

5. Lasater K. Clinical Judgment development: Using Simulation to Create an Assessment Rubric. J Nurs Educ. 2007a;46(11):496-503

6. Lasater K. Effects of high fidelity simulation on development of students' clinical judgment: students' experiences. J Nurs Educ. 2007;46(6):269-276.

7. Tanner C. Thinking like a nurse: A research-based model of clinical judgment in nursing. J Nurs Educ. 2006;45(6):1-9. 